\title{
¿Quién es El artista?
}

Who is El artista?

Quem é El artista?

\section{Cristian Molina}

UNIVERSIDAD NACIONAL DE ROSARIO, ROSARIO/CONICET, ARGENTINA

Profesor adjunto interino de Literatura Francesa en la Universidad

Nacional de Rosario (UNR) e investigador asistente del Consejo

Nacional de Investigaciones Científicas y Técnicas (Conicet).

Doctor en Humanidades y Artes, mención Literatura (UNR).

Ha publicado artículos sobre literatura latinoamericana y

francesa en diversas revistas. Es autor de Relatos de mercado.

Literatura y mercado editorial en el Cono Sur (Fiesta E-diciones,

2013). Correo electrónico: molacris@yahoo.com.ar

\section{Artículo de reflexión}

Documento accesible en línea desde la siguiente dirección: http://revistas.javeriana.edu.co Este artículo está dedicado a Juan Fernando García y a Cristian Godoy, quienes

colaboraron mediante un concurso en Facebook con información esencial para avanzar en la investigación. También quiero agradecer a Daniel García, por su ayuda.

doi:10.11144/Javeriana.cl20-40.qeea 


\section{Resumen}

En el presente artículo nos proponemos abordar la película El artista (2009) y el libro El artista (2010) como mutaciones de una misma práctica artística participativa que genera umbrales entre las distintas disciplinas y las afecta en diversos niveles, hasta someterlas a una especie de indeterminación autoral que les permite generar pequeñas e imperceptibles fisuras al dispositivo clasificatorio del mercado cultural en el que se inscriben, pero de cuya hegemonía en el arte anticipan su final.

Palabras clave: artista; participación de las artes; autoría participativa; firmas; mercado

\section{Abstract}

We propose to address in this article the movie El artista (2009) and the book $E l$ artista (2010) as mutations of the same participative artistic practice which creates thresholds between different disciplines. These affect them at different levels until they are submitted to a sort of authorial indetermination, allowing them to create small and imperceptible cracks on the classification device of the cultural market they subscribe to while anticipating the end of its hegemony over art.

Keywords: artist; participation in arts; participative authorship; signatures; market

\section{Resumo}

No presente artigo visamos abordar o filme El artista (2009) e o livro El artista (2010) como mutações de uma mesma prática artística participativa que gera umbrais entre as diferentes disciplinas e afeta-as em diversos níveis, até sometê-las a uma espécie de indeterminação autoral que lhes permite gerar pequenas e imperceptíveis fissuras ao dispositivo classificatório do mercado cultural no que são inscritos, mas de cuja hegemonia na arte antecipam seu final.

\section{Palavras-chave: artista;} participação das artes; autoria participativa; firmas; mercado

RECIBIDO: 10 DE SEPTIEMBRE DE 2015. ACEPTADO: 3 DE NOVIEMBRE DE 2015. DISPONIBLE EN LÍNEA: 1 DE JULIO DE 2016

Cómo citar este artículo:

Molina, Cristian. "¿Quién es El artista?”. Cuadernos de Literatura 20.40

(2016): 119-140. http://dx.doi.org/10.11144/Javeriana.cl20-40.qeea 
I.

En mayo de 2009 se estrenó la película El artista (2008), dirigida por Mariano Cohn y Gastón Duprat. Su argumento es ya conocido: un enfermero, Jorge Ramírez, interpretado por el músico retrovintage, Sergio Pángaro, presenta como obra propia los dibujos de Romano, uno de los pacientes de un geriátrico, que es interpretado por Alberto Laiseca. Ese acontecimiento lleva a Jorge por diferentes aventuras en el medio artístico hasta convertirse en una de las estrellas de las artes visuales del momento. La imagen que abre el relato es un plano fijo que, hasta que no se efectúa el contraplano siguiente, desconocemos que era una mancha de humedad que miraba Jorge Ramírez. Al principio, la extensión del tiempo en la focalización de la primera imagen parecería remitirnos a una pintura abstracta, lejos de lo figurativo, en la que predominan los tonos ocres y negros. De inmediato, pasamos a un plano general con un encuadre también pictórico, pero figurativo y caracterizado por una simetría y armonía en la distribución espacial.

De modo que desde el inicio, el filme evidencia la participación entre cine y artes visuales, al punto de que estructura la cualidad pictórica del plano fijo. Pero lo hace a partir de saltos del ojo entre lo abstracto y lo figurativo. Carolina Soria sostiene que este tipo de planitud con encuadres entre lo figurativo y lo abstracto remite a la historicidad de las imágenes entre lo clásico - Renacentista - y lo moderno, que constituye una particularidad del montaje heterocrónico de la película. Soria asegura que así se produce "la coexistencia y relación que mantienen los sistemas de representación clásico y moderno que caracterizaron dos periodos fundantes tanto en la historia del arte pictórico como en la historia del cine" (6). Coexistencia y relación, plantea la autora, pero por qué no pensar que en realidad lo que ocurre en la imagen es la participación al mismo tiempo de dos artes diferentes que convergen en una misma imagen, componiendo un umbral compositivo?

El grado de participación y, por ende, de contacto entre cine y pintura llega a un efecto máximo en los planos subjetivos que propenden en la película a trazar un paralelo entre encuadre cinematográfico y marco pictórico. Esto se condensa en los momentos en que los espectadores de las pinturas de Ramírez las miran; pero sin que en toda la película nosotros, en cuanto espectadores de cine, podamos verlas y generemos, de este modo, una travesía de la mirada del espectador de la pintura a través de la pantalla hasta encontrarse con la nuestra. Hal Foster plantea que uno de los posibles efectos de lo real en el arte se produce por un ilusionismo traumático que traspasa el tamiz pantalla de la mirada, haciendo que se toque lo real, por ejemplo en Autorretrato doble, de 1976, de Richard Estes, donde el artista se pinta mirándose reflejado en una vidriera, con lo que remite a un encuentro entre la mirada del mismo artista en su representación, dejándonos 
sin poder discernir lo que está dentro de lo que está fuera de esa espacialidad. ${ }^{1}$ En ese punto en el que algo escapa a la pantalla tamiz, pero está anunciado en una huella traumática, se encontraría lo real.

En El artista, sin embargo, las miradas encontradas son las de los espectadores, que nos dejan en un mismo nivel que la pantalla-tamiz y nos hunde allí a partir de una proximidad máxima que tiende a anular las distancias. Lo real que emerge de El artista es el artificio en el que se sostienen no solo nuestras miradas, sino la de los espectadores de las pinturas y, por ende, remite, de este modo, a reafirmar la situación de la mirada y de los juicios que se vierten sobre el arte y el artista delante de la obra (pictórica/cinematográfica), que son piezas de una ficción participativa. Esta planitud nos enfrenta, en términos de Didi-Huberman, a lo ineluctable de todo acto de ver. Es decir, a la situación paradójica que supone el acto de ver, en el cual lo que vemos nos mira mientras la visión choca con un obstáculo que se toca con el cuerpo, pero que en sí es puro vacío. Lo ineluctable toca una pérdida desde la cual nos mira y desde entonces nos asedia. Por eso, para Didi-Huberman, el plano óptico implica un trabajo del síntoma en el que lo que vemos es una obra perdida a la que se nos remite: "lo visible es ineluctable cuando ver es sentir que algo se nos escapa ineluctablemente: dicho de otra manera, cuando ver es perder" (18).

Así, mediante encuadres ilusionistas, la película, a partir del encuentro de miradas, sumerge nuestra visión y juicios del arte en su planitud que es la obra de Romano ausente. Casi como si por ese agujero de la obra y de su silencio, los deslices de las miradas y de los juicios se volviesen la obra misma de una interrogación sobre el arte, pero también potenciando, de ese modo, la intriga sobre quién es el artista en el mundo contemporáneo, que es la pérdida que sostienen esas miradas. Porque al invisibilizar la pintura de Romano, lo que queda es la pura tensión con la firma de Ramírez, también, como el otro nudo de la imagen.

Es decir, no se trata solo de los juicios y valores que se esgrimen desde la doble mirada que se encuentra en el espacio pictórico cinematográfico del encuadre/marco de los planos/pinturas, sino, además, de la interrogación de una obra

$1 \quad$ Foster asegura: "Ante estas pinturas uno puede sentirse bajo la mirada, observado desde muchos lados: así ocurre con la imposible perspectiva doble que Richard Estes persigue en Union Square (1985), la cual converge sobre nosotros más que se extiende desde nosotros, o su igualmente imposible Autorretrato doble (1976), en el que miramos la ventana de un comedor totalmente perplejo respecto a lo que está dentro y lo que está fuera, lo que está delante de nosotros y lo que está detrás. Si Union Square exprime un paradigma renacentista de la perspectiva lineal como La ciudad ideal, Autorretrato doble exprime un paradigma barroco de la reflexividad pictórica como Las meninas" (146). 
ausente que es firmada por Ramírez, aunque sepamos como espectadores que la produce Romano. Es la huella de esa ausencia la que remite al vacío indeterminado e indefinido de una obra firmada y producida por dos personas diferentes lo que se convierte en central durante toda la película. Por eso, como aseguraba Soria, se da esa tensión de planitud pictórica que remite a dos momentos del arte bien diferenciados: uno clásico, en el que la figura del autor-artista y el productor de la obra implicaba una homologación; y otro moderno, donde autor-artista y productor no siempre coinciden, al menos desde los ready made de Duchamp, sobre los cuales la película se detiene en uno de los parlamentos de Jorge Ramírez.

En efecto, él mismo asegura, mientras hojea un libro de arte con análisis de la ya clásica firma del mingitorio de Duchamp, que "Si yo agarro esto, un teléfono, cualquier cosa, y lo pongo en un museo, y digo: 'Esto es arte', ¿isoy un artista?" (Soria 69). Esta inquietud es tal que, ante la pregunta frente a Duchamp que se da en la película, el libro introduce un monólogo de Romano donde este responde a la pregunta de Ramírez: "No. Pero en cambio sos puto". Es decir, el libro yuxtapone dos versiones sobre el artista en los parlamentos y monólogos de los protagonistas, a través de una pregunta retórica sobre un libro de arte, institucionalizado, y una respuesta negativa, mientras que en la película los protagonistas prácticamente carecen de palabra y no hay respuesta, sino silencio. Lo que me interesa señalar es que, de este modo, con respuesta o sin esta, en ambos formatos se instala la pregunta por quién es el artista.

Esta pregunta es central, porque remite a las condiciones actuales en que se define el artista relacionado con, por ejemplo, la diferencia que Bourriaud (Postproducción y Radicante) entiende entre un artista en el marco de la posproducción contemporánea, con una concepción más clásica (si bien Bourriaud piensa en términos de modernidad), y con las diferencias entre lo que ciertos colectivos de artistas hacen mediante instalaciones, ensambles y reciclados, donde los productores no siempre coinciden con el artista que firma la obra y la coloca en un museo, como puede leerse en su libro Radicante. Por ende, la pregunta en El artista no es tanto qué es un artista ni qué es el arte contemporáneo, sino quién es el artista dadas estas condiciones de valoración y de producción del arte en cuyas miradas nos encontramos. La ausencia a la que nos enfrenta la mirada es la de una obra en la que nos tocamos sin ver y de la cual no podemos saber quién es el artista.

La pregunta es tan potente que en la materia sonora misma de la película, que abre al fuera de campo, también se remite constantemente a una relación asimétrica entre banda musical y sonidos del mundo - voces, bullicio, ruidos y conversaciones-, que vuelve a interrogarse sobre el artista en el mundo con- 
temporáneo. La banda sonora es una fusión tecnoclásica que pertenece a Diego Bliffeld y aparece muy pocas veces, sobre el principio y el final. El músico Sergio Pángaro permanece prácticamente mudo y apenas si en los títulos de la película se lo oye interpretando, fuera de su rol de Jorge Ramírez, Crudo amore, un bolero italiano romántico en tono vintage. Lo demás está orquestado por silencios, voces y diálogos de los personajes, muchas veces provenientes del fuera de campo y que se homologan como si fueran una cortina musical. Y debido a la planitud pictórica, la película adquiere, por momentos, los visos del cine silente, sostenido por gestos, pero a diferencia de la cualidad expresiva que Béla Balázs pretendía en la actuación silente, aquí los protagonistas son inexpresivos, con un tono apagado en el que apenas hablan. ${ }^{2}$ Romano solo menciona la palabra apelativa pucho y Ramírez es reticente para hablar, al punto de que en un paseo por la galería de arte, una de las guías sostiene que cuando le preguntó qué pretendía lograr con su obra, solo obtuvo un silencio magistral. Tal es así que la película está adelgazada en sus diálogos, como ocurre en la mayoría del cine argentino desde los años noventa. Sin embargo, las conversaciones fuera de campo, los ruidos de las multitudes o las voces de personajes que permanecen fuera del plano atraviesan las imágenes como una banda sonora que contrasta con el estilo tecnoclásico de Bliffeld y con el melódico de Pángaro, que nos hace percibir una sonoridad que pone en un mismo fuera de campo a la banda sonora y el ruido del mundo, y que, por eso mismo, el artista - en cuanto músico-desaparece o es reducido al mínimo como actor o en las pocas veces en que irrumpen los temas en que son intérpretes, pero yuxtapuestos, perdidos, con el bullicio del mundo que se advierte en el fuera de campo.

Entonces, en El artista se trata de que la imagen cinematográfica adquiera cualidad pictórica, simule y construya encuadres pictóricos y que, por ende, lo pictórico se convierta, así, en el marco de un relato fílmico que se interroga sobre el artista de una obra ausente. Sin embargo, esta cualidad pictórica exaltada por el plano fijo, ya había sido implementada por Duprat y Cohn en Enciclopedia (el proyecto comienza en 1996, pero se estrena en 2000), un montaje documental de escenas bajo una mirada antropológica de la sociedad de la década de los noventa, en la que aparecían planos con entrevistas, performances, presentaciones, promociones, tomas espías, tanto de personas desconocidas como de artistas reconocidos. ${ }^{3}$

Me interesa detenerme, de momento, en algunas entradas de la enciclopedia cinematográfica, por ejemplo, en el plano medio y fijo en el que una niña

\footnotetext{
2 "En el cine, el habla es mímica y expresión inmediatamente visual del rostro" (Balázs 40).

3 La dirección del documental es tripartita, puesto que Adrián de Rosa también participa de ella.
} 
interpreta una coreografía mientras ocupa el centro del encuadre. Porque estos planos, también pictóricos, serán una constante en las imágenes de Cohn y Duprat del programa Televisión abierta (1998), que se trató del primer delivery televisivo que consistía en la captura de imágenes a pedido por los espectadores, que luego eran editadas y puestas al aire, en un montaje similar al de Enciclopedia, aunque con ciertas diferencias, como el uso de la voz en off de un locutor o, a posteriori, de ciertos invitados famosos que iban con el equipo pedido a casa de los espectadores. Puede pensarse como una toma de la pantalla televisiva por los espectadores que produce, según Cohn y Duprat, la emergencia de "lo intelevisable" a partir de imágenes con cuerpos y fondos que la televisión argentina dejaba fuera (véase Speranza 35). Lo que me interesa remarcar de momento es que si las imágenes también reproducían tanto en Enciclopedia como en Televisión abierta la misma cualidad pictórica, mucho más clásica en el caso televisivo, pero en la misma tensión con lo moderno señalada en El artista en el documental estrenado en 2000, también se volvía a insistir con la inquietud por el arte y la participación de algunos espectadores que interpretaban coreografías, recitaban poemas o cantaban frente a la cámara. Es decir, tanto en el documental como en el programa televisivo, así como en la película y en el libro del que nos ocupamos, la pregunta sobre quién es un artista en la cultura contemporánea volvía a instalarse por la irrupción en la imagen de cuerpos que ejecutaban un arte frente a la cámara. Cuerpos que, además, eran los de los espectadores que se sumergían en la imagen y formaban parte de ella, trasponiendo la mirada de la pantalla. Ese interrogante se condensaba mucho más cuando algunos de los espectadores artistas del programa saltaban a la fama como el músico Zambayonny y como la banda de cumbia Las Dagor's. Este nudo extendido entre los formatos, además, se vuelve aún más evidente cuando en la famosa escena del filme que analizaremos en el siguiente apartado, en que los internos miran hacia el fuera de campo, se oye el jingle del programa Televisión abierta, pero también cuando Ramírez confecciona su currículo en el departamento del vecino fotógrafo, el encuadre deja ver en una de las paredes un afiche con una promoción del músico Zambayonny.

Entonces, la composición posiciona la imagen entre pintura, cine y televisión, lo cual se sostendrá en una gran parte de la película El hombre de al lado (2011), también de Duprat y Cohn, en el encuadre enmarcado de la ventana de Víctor (Daniel Aráoz), que se observa desde la casa Curuchet, donde vive Leonardo (Rafael Spregelburd). Sin embargo, hay varias diferencias con El artista que terminan decantando en una hipermoralización final de los estereotipos de los protagonistas bajo un binarismo cercano al de civilización/barbarie, artista/no artista, ley/crimen que resulta problemático. De todos modos, el procedimiento 
vuelve a ser el mismo: el plano de una ventana que adquiere cualidades pictóricas por un marco rectangular de madera resaltado a partir de un cruce de miradas entre los protagonistas, intercalado con planos donde la niña de la familia baila en el encuadre de su habitación de la misma manera que los protagonistas de Televisión abierta, y planos de una ficción de títeres perversa que se desarrolla en el interior del marco de la ventana en el departamento de Víctor. Pero en este caso, la mirada interfiere con las miradas cruzadas de los protagonistas y resalta una tensión binaria que moraliza toda la película y que termina de cerrarse sobre el final, donde el estereotipo del creativo diseñador, que se encontraba del lado de la ley institucionalizada por el derecho penal, se pone del lado del código también de la ley popular y deja morir a su adversario insinuantemente perverso como la única forma de salir de una situación de asedio. Incluso este binarismo se extiende hasta el nivel artístico, donde el profesional del diseño es exitoso y puede vivir de su labor, siendo referencia en su especialidad; mientras que el vendedor de autos si bien hace arte, realiza adefesios de fuerte contenido sexual (esto es "una concha", asegura Víctor cuando le ofrece una escultura propia como regalo a Leonardo) que se convierten en una molestia para los gustos refinados del diseñador, pero que también remarcan el carácter pedófilo de la representación de títeres de Víctor, con contenido sexual que hace mirar por el marco de la ventana a la pequeña hija de su vecino. Así, el interrogante por el artista y el arte rompe la indeterminación con la emergencia de un marcado punto de vista clasista y elitista, incluso estereotipado. Punto de vista que en el final de la película emerge con toda su potencia cuando la ley del diseñador triunfa, cometiendo un abandono de persona. Digamos, por la hipermoralización de la película, en la que se demoniza a quien se hace el artista, ese abandono de persona queda prácticamente justificado.

Sin embargo, no quiero decir con esto que el desmantelamiento de la pregunta que se sostenía en una ausencia en El artista sea una recaída en un moralismo bienpensante y culterano de la dirección de Cohn-Duprat, sino que forma parte de un despliegue mutante del sentido que el dispositivo cinematográfico lleva hasta la contradicción y que escapa, incluso, de cualquier intencionalidad de la dirección que muchas veces se declara respecto de la película en diversas entrevistas (véase Duprat y Cohn, "Esta película"), sobre todo cuando se produce el encuentro de la imagen con el relato literario a partir del libro que en 2010 escribe Alberto Laiseca y publica por la Random House Mondadori. Lo interesante es cómo Laiseca, con esa publicación, salta de no actor de una película a ser autor del libro que en la portada se anuncia como "adaptación libre de la película", cuyo guionista era Andrés Duprat. De la actuación a la escritura, del 
cine a la literatura, la presencia de Alberto Laiseca cobra una nueva dimensión, porque cuando observamos su trayecto en la apuesta cinematográfica completa de los dos directores y de su guionista, ese carácter de mera "adaptación libre" resulta, cuanto menos sospechoso, y sobre todo cuando el escritor que compone la novela viene ejecutando una estética del plagio desde la década de los noventa en la literatura argentina.

En la película El artista no era la primera vez que Laiseca formaba parte del trabajo fílmico y audiovisual de la dupla Duprat-Cohn. En efecto, aparece por primera vez en el documental Enciclopedia, donde narra un cuento: un personaje con poderes mefistofélicos le da la posibilidad de volver a vivir, pero exactamente igual, en cinco minutos, diez años de su vida a un hombre en cualquier momento del pasado. Sobre el final, Laiseca, que no para de fumar, sostiene: "es la misma historia de siempre, pero contada modernamente". En 2011, Duprat y Cohn estrenan Querida, voy a comprar cigarrillos y vuelvo, basada en un "cuento inédito de Alberto Laiseca", con la participación de él mismo como narrador, que tampoco deja de fumar. El cuento inédito es la variación fílmica de aquel microrrelato que aparecía en Enciclopedia, luego de que Laiseca también hubiera participado como narrador en Cuentos de terror (2004), un programa televisivo que se emitió por I-SAT, bajo la dirección de contenidos de Ralph Haiek y cuya idea original fue de Gastón Duprat y Mariano Cohn; pero también luego de que haya trabajado como actor en El artista y, por ende, de que haya escrito el libro sobre esta. La película de 2011, sin embargo, somete a variaciones considerables el cuento inicial. Cuando Ernesto Zambrana (Emilio Disi/Luciano Lopilato), un agente inmobiliario, se encuentra con el "Inmortal" (Eusebio Poncela), este no le plantea como condición que no altere el pasado, de modo que Ernesto vuelve, no una, sino tres veces en el tiempo, a fin de tratar de recomponer situaciones pasadas. En dos ocasiones intenta salvarse plagiando, la primera vez, un programa de televisión, Gran hermano, antes de convertirse en un éxito mundial, y la segunda ocasión Imagine, el tema musical de John Lennon, que lo convierte en una estrella nacional, hasta que es denunciado por robar los derechos de autor del tema que se había convertido en un hit. Querida, voy a comprar cigarrillos y vuelvo regresa a Laiseca para filmar una mutación de su cuento inédito presentado en Enciclopedia. En las dos, Laiseca no deja de fumar, del mismo modo que en el ciclo Cuentos de terror cuando versiona grandes relatos de la historia de la literatura para el formato televisivo. Si hago hincapié en este detalle, es porque en El artista, Laiseca, que está obligado a actuar, pide pucho todo el tiempo, como si estuviera desplazado de su función y sometido al arbitrio y la dependencia del relato de otro. En efecto, su participación en El artista lo relega a un papel actoral 
por fuera de las performances narrativas del documental, de la televisión o de la película de 2011; allí Laiseca se pone en el cuerpo de Romano, el que produce el arte que firma Jorge Ramírez. Este juego de versiones y reversiones nos remite a la apuesta de Laiseca por el plagio en Por favor, ;plágienme! (1991), como si el relato cinematográfico se hiciera cargo de un problema por el artista como escritor plagiado y plagiario, que ya estaba presente, también, en la literatura argentina.

Es decir, ya estamos en el nudo en que cine, televisión, artes visuales, música y literatura tienden a participar de una misma experiencia artística, pero ahora vía Laiseca y su idea del plagio. Uno que hasta la edición del libro El artista, escrito y firmado por Laiseca, en 2010, no se hace efectivo como preocupación en la trayectoria de Cohn-Duprat. Es el plagio que el libro efectúa de la película, como una especie de revenge que se toma el mismo artista que actuaba de creador sin firma en ella, el que desplaza la ausencia de respuesta sobre quién es el artista que la película sostenía. Es decir, se trata de una toma por asalto del relato original de Andrés Duprat por parte de Laiseca, por medio del cual se introducen variaciones para nada mínimas en el libro. En principio, emergen pequeños monólogos interiores de Ramírez y de Romano que estaban ausentes en la película, como si el libro cubriese los huecos vacíos y silentes de la imagen fílmica. En esos monólogos, sin embargo, como asegura Carlos Fernández González se le otorga un carácter criminal al plagiario que es funcional a la figura del mismo que Laiseca viene diseñando desde Por favor, ;plágienme! En un punto, el plagio, en el mundo de Laiseca, hace del plagiario un artista del mal para la moral literaria del genio romántico, del creador o del inventor de historias. Esas dos perspectivas se ponen en abismo, todo el tiempo, en los monólogos, mediante un particular sistema de injurias y discursos complacientes que tanto uno como otro protagonista sostienen.

Claro que ya desde Por favor, iplágienme! Laiseca ponía en juego una compleja moral del plagio que adquiría diversos matices, desde la copia idéntica injuriada y condenada como mal plagio hasta un tipo particular y positivo, que consistía en el rediseño de un molde por variaciones mínimas o hasta volverlo irreconocible con el precedente de donde fue tomado. El plagio de Ramírez está próximo al primer tipo de plagio; sin embargo, como en la película, el libro postula la posibilidad de imitar el trazo de Romano, cuando este ha muerto en Roma, para producir nueva obra: "Todos podemos. Y yo más, porque estuve aprendiendo. ¿Cómo hacía el viejo? Más vigor en el trazo. Eso" (Laiseca et al. 16). O sea, se plantea la posibilidad de haber devenido artista, primero mediante el robo de la obra de Romano a la que se le asigna el nombre propio, pero tras su muerte, de un modo nuevo a partir del intento de copia de un trazo para producir más obra. Y 
esa posibilidad se abre al mismo tiempo que, como señalamos precedentemente, Romano asegura que no, que no es un artista ante la pregunta que Ramírez realiza a propósito del procedimiento de ready made de Duchamp.

Por lo tanto, el libro construye un umbral indeterminado, entre la condena del plagio y su posibilidad como acto artístico, incluso en el mismo personaje, que es donde se abre nuevamente la ausencia de respuesta definitiva, pero desde la literatura, a la pregunta sobre el artista que estructuraba el filme. Si una vez muerto Romano, Ramírez, devenido artista por la obra ajena, comienza a producir nueva obra, con características semejantes, pero diferentes, ¿quién es, entonces, el artista? Y no es menor que el libro empiece continuando el final de la película. En ese comienzo del libro que la película clausura, porque termina con la muerte de Romano, se escribe un después posible del tiempo fílmico donde Ramírez en el libro tiene la posibilidad de devenir artista por medio del plagio. De modo que como en Por favor, iplágienme!, en el libro El artista, se condena un tipo particular de plagio, al mismo tiempo que se habilita la posibilidad de que este, no obstante, pueda hacer devenir paradojalmente al mismo o a otro, un artista. Como vemos, no se trata de la moralización excesiva y dicotómica entre artista auténtico/inauténtico, artista del don/profesional, sino que se pone en evidencia cómo un mismo procedimiento puede hacer que todo sea posible y que resulte, a veces, un verdadero problema para la calificación de artista detentada positiva o negativamente sobre una persona en el mundo contemporáneo.

Hernán Bergara asegura que Por favor, iplágienme! es un texto conspirativo y sospechoso, porque se ubica más allá de la apología o el rechazo del plagio y arrastra, de ese modo, la desvergüenza de toda invención y del mito romántico del arte como actividad creadora. Lo hace, plantea, instalando una zona entre lo aceptable y lo inaceptable a partir de un "discurso ficcional reversible" como toda la ficción de Laiseca. Quizá por esto, Ricardo Piglia sostenga que "Las novelas de Laiseca tienden a construirse como una enciclopedia. Son novelas del saber absoluto" (Prólogo a Los Sorias). Porque la reversibilidad de la ficción y la construcción de umbrales entre lo aceptable y lo inaceptable, lo propio y lo ajeno en el que se sostiene la ficción de Laiseca, tienden a agotar todas las posibilidades del relato, todas sus versiones y, por ende, todas las versiones posibles sobre el plagio y el plagiario, para construir una enciclopedia total que contemple todas las entradas posibles en esa definición, alejándose de cualquier determinación moral.

Si esto es así, la escritura del libro El artista es una extensión, en cuanto pliegue mutante de la "obra conjunta" de "Alberto Laiseca, los hermanos Duprat, Mariano Cohn, León Ferrari" (Chitarroni, citado en Laiseca et al. 9). Es decir, una vuelta más en calidad de versión sobre una historia plagiada del guión 
original de Andrés Duprat, gracias al encuentro de la imagen televisiva, pictórica y cinematográfica con el relato laisequeano de la literatura. La escritura del libro plagia como revenge del artista plagiado, la historia de Duprat, y a partir de entonces la extensión del relato del plagio entre el cine, la literatura y las artes visuales mutará no solo toda la trayectoria de Laiseca bajo la dirección de Cohn y Duprat, sino que comenzará a socavar la atribución autoral de las historias narradas: la de la película en el libro, en primer lugar, pero también el autoplagio de la misma historia de Enciclopedia en la filmografía de Duprat-Cohn.

Entonces, la versión del problema sobre el artista que aparece en El hombre de al lado, en la que Laiseca colabora con el guión, debe entenderse como una mutación más de la reversión de la ficción literaria de Laiseca en la que la imagen cinematográfica participa, no como una simple respuesta condenable desde la estereotipia moral que parecería proponer, sino que esa estereotipia moral es el efecto de una participación entre el cine, la literatura y las artes visuales que "la obra conjunta", y en distintos formatos, promueve. Así, el doble pliegue de la apología y rechazo del plagio literario, cuando entra en contacto con la pregunta sin respuesta sobre quién es el artista, muta en reversibilidad fílmica, abriendo versiones contradictorias y paradojales sobre el artista y sobre el plagio. La pregunta sobre quién es el artista encuentra en El hombre de al lado (2010) una reversión ficcional moralista que ofrece, lejos de la versión sobre la indeterminación de la definición de artista en el arte contemporáneo del filme de 2008, una versión elitista, existista y clasista que, a su vez, en 2014, se revierte en la película de Duprat-Cohn Living Stars, donde nuevamente los espectadores devienen artistas como en Televisión abierta, reproduciendo el montaje de Enciclopedia y ofreciendo, por ende, una definición de artista masivo y popular en la extensión del relato fílmico.

Mientras que el problema del plagio en el libro El artista es una versión del guión de la película de Andrés Duprat, en un verdadero plagio de Laiseca, luego esta situación se revierte en la ficción fílmica de Querida, voy a comprar cigarrillos y vuelvo, con un guión original de Andrés Duprat tomado del cuento narrado por el escritor en Enciclopedia. La cualidad reversiva, plagiaria y de versiones paralelas de la literatura de Laiseca, a partir de El artista, se pliega con la cinematografía de Cohn-Duprat para abrir todas las posibilidades sobre la presente ausencia de respuesta unívoca ante la pregunta quién es artista en el mundo contemporáneo, en un momento cuando, en términos de Laddaga, todos quieren serlo. 
II.

Entre la película, el libro y los diferentes medios (internet, periódicos o revistas culturales) donde circula $\mathrm{El}$ artista, insiste una imagen común (véanse Finkel; McNamara; Krapp). Es la que corresponde al extenso plano fijo que se encuentra al principio del filme, donde Romano y otros internos miran un punto sobre sus cabezas en el fuera de campo. La escena dura cuarenta segundos en total en la que parece no suceder nada. Pero a los diecisiete segundos ingresa Jorge Ramírez y se prepara para sacar de escena a Romano, hasta que finalmente lo hace. El encuadre reproduce una perspectiva extendida a un punto de fuga habilitado por las puertas abiertas que tienden a proyectar la mirada en el fondo; y casi como en una película de Antonioni, allí el espacio se geometriza para abrirse a varios umbrales proyectados y adornados con frisos florales y guirnaldas en las paredes blancas contiguas. Pero apenas empezamos a prestar atención a los detalles del sonido, nos damos cuenta de que los internos miran televisión, y que el programa que oyen es Televisión abierta. Y vemos que se trata de reconocidos artistas y personajes de la cultura argentina: junto a Laiseca y Pángaro, participan Rodolfo Fogwill, León Ferrari y Horacio González como actores. Esa escena tiene la potencia de condensar, por un lado, la participación artística que estructura $E l$ artista; pero, también, presenta, al menos, dos problemas subsidiarios que están relacionados con la pregunta por quién es el artista en el mundo contemporáneo de la que hablamos precedentemente: por un lado, el peso de las firmas de artista; pero fuera de su pertenencia disciplinar, es decir, haciéndolos actuar siendo no actores, junto con otras firmas con las que la película y el libro las anuda; por el otro, esas mismas firmas, así como la insistencia con que se promociona la película en esta imagen, hace ingresar el mercado con su producción de marcas y de logos como una de las preocupaciones centrales relacionados con esa pregunta.

Este proceso de aparición de firmas artísticas se sostiene en que actúan de no artistas, algo que podría extenderse, no sin reparos, al caso de Pángaro y Laiseca sobre los cuales el relato fílmico plantea la pregunta por quién es el artista sin resolverla. Y en este sentido, al mismo tiempo que su potencial de firmas de artistas se sostiene en las imágenes de los dos formatos, tanto en el cine como en el libro, pero también por fuera de ellos, en las reseñas de ambos, su cualidad de artistas está suspendida haciéndolos participar en el caso del filme como no actores que, sin embargo, actúan. Jens Andermann, en $\mathcal{N}$ uevo cine argentino, sostiene que una de las características de la cinematografía de los últimos años consiste en proponer performances actorales que cuestionan los estilos autorales y reconfiguran los géneros narrativos. Por eso, sostiene, quizá más que nunca, hoy la figura del director-autor sea la menos adecuada "para describir un proceso en el que 
la mayoría de los profesionales alternan roles" (214). Esto puede, desde su punto de vista, dar cuenta, en el caso de algunas películas como Los rubios, Estrellas o El bonaerense, de un discurso performativo sobre lo que significa hoy hacer una película como producción negociada y colaborativa de acontecimientos con un sujeto de enunciación colectivo e individual a la vez. Lo que me interesa señalar de esta hipótesis de Andermann es, en primer lugar, ese carácter de alternación de roles al que tiende el cine y que busca poner en primer plano en su práctica contemporánea, y que involucra, al mismo tiempo, problemas sobre la autoría como performance actoral colaborativa. Porque lo que sostengo es que El artista, a partir de la performance actoral de las firmas de artistas que involucra, promueve una performance autoral que, al tiempo que exhibe en su producción y en la imagen la centralidad de la firma en el arte contemporáneo, cuestiona la autoría como autoridad de esa firma en relación con su propia obra y con el mercado. Esto último se produce a partir de un sistema participativo que tiende a borrar los límites entre la atribución de propiedad intelectual de parte de los distintos sujetos que pone en acto, provenientes de distintas artes que se reúnen en un trayecto extendido en el tiempo, más allá de El artista, pero siendo este el punto de condensación que evidencia y pone en juego todo el proceso, cuestionándolo.

Fogwill, Laiseca, Pángaro, González, Ferrari actúan sin ser actores y se suman en la película y en el libro a una constelación de firmas. En la película, a los nombres Andrés Duprat como crítico de arte que actúa en El artista como curador, también sin ser actor, pero de la profesión que efectivamente realiza como tal por fuera de la actuación, algo que, en el libro se repone con su firma en un texto que se anexa al final: "Apuntes sobre el arte contemporáneo". Allí, Duprat sostiene que "el escenario de validación del arte contemporáneo se fue consolidando con figuras funcionales e imprescindibles al establecimiento de un circuito de valoración, cuyos pilares han sido el marchand, el curador y el coleccionista" (Duprat, citado en Laiseca et al. 125). De este modo, continúa, "el mercado del arte así constituido extremó los viejos conceptos de originalidad y obra única, sobrevalorándolos al límite de la extrañeza que puede provocar el precio alcanzado por una obra" (126). En ese anexo aparecen elementos que en la película no estaban. La necesidad de Duprat de atribuirse la autoría de El artista, al tiempo que un conjunto de marcaciones autorales que pretenden contestar a algo que la película no necesariamente revela desde su construcción y trabajo con una respuesta ausente que se trama en la obra ausente en sí misma para la mirada. De esa zona ciega, el libro, pareciera por momentos, a través de un sofisticado agregado de firmas como las de Duprat, desplegar respuestas parciales que tratan de cerrar los silencios mediante afirmaciones como "Alberto Laiseca, genial 
escritor" o "Sergio Pángaro [...] sobre todo es un artista". Sin embargo, las otras firmas que aparecen allí ponen en entredicho no solo lo que Duprat menciona en relación con ese sentido ausente, sino incluso su propia autoría, y así contradice las declaraciones por momentos de trinchera del guionista.

Luis Chitarroni, quien abre el libro con un prólogo, asegura que El artista (película y libro) es "una obra conjunta", que "más que autor solicita un elenco" que no es "nada complaciente"; además, asegura que en él "asistimos a un backstage de una consagración artística" que permite visibilizar que "la vida oscurece las diferencias entre la vida y el arte, como pregonaba (o acaso sólo implorara) Cage" (citado en Laiseca et al. 9). De modo que no solo piensa El artista en el sentido de performance actoral que se convierte en una autoral, ya que parece reclamar un elenco que actúa de autores y del cual, con su firma en el formato libro, Chitarroni pasa a formar parte, sino que entra en estrecha diferencia con las palabras paternalistas - y por momento arrogantes- del propio guionista.

Es una mutación de sentido en el espacio de un mismo libro que, como señalamos, intentaba, además, una nueva versión de sentido de la película, y que extrema este procedimiento con la otra firma que irrumpe en final con el texto "Hacer", de León Ferrari, quien sostiene: "Hacer cosas confusas, intrincadas, escondidas, dentro de un espacio simple, como un dibujo en un rectángulo de papel [...] hacer formas puras como una verdad pero tacharla, retorcerla, matarla con otra verdad y con otra cada vez más inestable, insegura" (Ferrari, citado en Laiseca et al. 135). No es un mero detalle que el texto de Ferrari, la firma Ferrari, cierre ese libro. En principio, porque ese texto viene a reponer, en algún punto, otra versión posible de El artista: la de un cúmulo de verdades (plásticas) tachadas, paralelas, coexistentes de una verdad que es inestable, insegura y, por ende, ausente y que se afirma como tal, lejos de negarse. Pero tampoco es un mero detalle porque la participación de Ferrari en El artista sigue la trayectoria de sus propias palabras que, si conocemos mínimamente la práctica artística de Ferrari, parecen remitir a ella misma. León Ferrari es, así, una firma que actúa como no actor de no artista en la película, que aparece en los créditos con una obra como artista sumado a una constelación de firmas que lo sitúan en ese rol (Miguel Mitlag, Laura Spivak, Tulio de Sagastizábal, Valeria Maculan, Lux Lindner, Cristina Schiavi, Daniel García y María Martins), que escribe el epílogo del libro, anunciándose en la tapa, y que produce la película, además. Y si extendemos la firma León Ferrari en sus relaciones con Duprat y Cohn, no solo aparecerá con obra en El hombre de al lado, sino que la productora Televisión abierta filmará el documental sobre su vida Civilización, con guión de Andrés Duprat y música de Sergio 
Pángaro. Lo que me interesa señalar es que aquí la firma León Ferrari muta de no artista a artista, a productor, a escritor en El artista y a protagonista en el documental de la productora de los dos directores de la película de los que muchas veces es socio. Esa mutación es, por un lado, consustancial con su concepción de "Hacer" que inscribe en el libro y en la película; es decir, el de un movimiento incesante y abierto hasta lo paradojal que reproduce, además, algunas concepciones sobre su propia práctica de artista. Y, por eso, en esas lecturas y declaraciones sobre El artista su firma se inscribe, así, como autor en tanto detalla de la película y del libro algo que, en realidad, define su propia práctica y trayectoria en ese espacio, así como sus ideas del hacer en relación con el arte. Pareciera que sus declaraciones se encontraran con la película y el libro, y lo dotaran de un carácter autoral que refleja la forma en que sí mismo se vuelve pieza de obra en El artista a partir de un magma de mutaciones contradictorias en que libro y película se encuentran, se tocan, se extienden, conformando una obra participativa y multisoporte.

En este punto, lo que cabe preguntarse es por esa entidad doble y cuestionada de por sí de la dirección de la película que se pone en acto y que se desestabiliza hasta borrarse en una multiplicidad autoral en su propio trazo fílmico. El director de la película es doble, no uno solo. Ya desde allí, algo enrarece la figura típica del director-autor que Andermann cuestiona para pensar el cine contemporáneo argentino en un umbral entre lo colectivo y lo individual, así como la del guionista-autor. Si las perspectivas clásicas de la cinefilia postulaban la figura del cine de autor como identificable, a veces, con el rol del director, las teorías más contemporáneas y la propia práctica fílmica parecen, ahora, cuestionar esa simple identificación. Esto no significa que la autoría y las firmas carezcan de valor; todo lo contrario, demuestran que las formas tradicionales ligadas a la individualidad o a la identificación singular de un único punto de vista se complejiza en estas prácticas de autorías colectivas que tienden a hacer tocar la práctica del arte contemporáneo casi con lo impropio y lo multisubjetivo: una participación autoral extendida y sostenida en diversos planos y soportes tanto formales como de sentido, intrínsecos y extrínsecos a la práctica misma.

En un libro riguroso y exhaustivo, Marcelo Topuzian indicó cómo desde diferentes perspectivas teóricas la figura del "autor" resucitaba luego de su muerte en la contemporaneidad. Hay varios recorridos teóricos que desde los años noventa se propusieron desandar el camino de esa resurrección. Topuzian es consciente de que el camino más débil es el que esquiva las discusiones sobre el mismo inauguradas desde los años sesenta por Barthes, Foucault y Derrida, 
generalmente provenientes de enfoques meramente culturalistas. Pero entiende que hay diversas perspectivas que atraviesan problemas sociológicos, filosóficos, culturales y hasta del derecho que, sin desconocer la limitación que supone un concepto de autoría como clausura el sentido de una obra, proponen al autor como aquello que "nombraría el momento en que la situación de la literatura resulta excedida por ella misma a partir de una singularidad que paradójicamente ya no puede nombrarse en esa situación" (301). En este sentido, piensa que en la aporía de una verdad crítica, no deberían descartarse la consideración de la autoría como diseminación de sentido más allá de lo textual, con una intencionalidad que no clausura, sino que es un elemento más de la significación entre otros. También plantea que se pueden separar en su estudio al sujeto del autor, así como su firma, su función autor y la instancia jurídica de la que se lo instituye a lo largo de la historia, como niveles que si bien juegan en el momento de la autoría no necesariamente se autodeterminan. Si bien este enfoque es específicamente literario, la participación de este discurso en la imagen fílmica de El artista, así como la performance plagiaria de Laiseca, nos habilitan a pensar esta noción en diversos planos, sobre todo en las escisiones y relaciones múltiples que la autoría implica, pero también en función de ese exceso diseminante que no puede nombrarse a sí mismo que la constituiría.

Por eso mismo, la definición amplia de autoría habilita a pensar lo que se pone en juego en El artista, en cuanto película y libro en la que intervienen diferentes firmas, pero también diferentes intencionalidades autorales. Aunque tenemos que advertir que en el cine, la música y la televisión, la relación entre firmas y autorías tiene un carácter muy diferente a lo que presupone en la literatura y en las artes visuales. Mientras las primeras tienden a apoyarse en relaciones indirectas entre firma y autoría, en la literatura y en la pintura (clásica), generalmente, hay una relación más directa entre firma y autoría. Esto se explica porque las firmas de una película no incluyen solo la del director, que es generalmente el que se asimila con la función autor, aunque no necesariamente con los derechos de propiedad que suelen pertenecer al productor, sino que involucran, además, las firmas de las estrellas que dotan al mismo de un valor singular tanto como la firma de la dirección (véanse Jullier y Leveratto; Gardies). En el caso de la música, las relaciones entre intérprete, cantante y a veces banda o conjunto también implican diferentes articulaciones no tan directas entre firma y autoría (tanto función autor como derechos de autor) y, a veces, una autoría colectiva. En cambio, en la literatura y la pintura, esas relaciones son más directas, si bien también intervienen las firmas editoriales en la atribución de derechos de autor y si bien la asociación entre autor, sujeto, firma e imagen, como explica Topuzian, siempre 
dan lugar a un resto inasible. Por eso, quizá, se den estas flexiones tan particulares en las participaciones de Laiseca y Ferrari cuando intervienen y dotan de una intencionalidad autoral que se sobreimprime no solo sobre el autor del guión de la película, sino, además, sobre la práctica cinematográfica y de producción de la dupla de los directores. En cambio, Sergio Pángaro es reducido en su intencionalidad autoral; aparece mínimamente como intérprete del tema de los títulos de la película, con un estilo que remite a su propia práctica en la banda retro melódica Baccarat, y como actor, o en la banda de sonido de las demás películas de los directores y de la productora. De modo que se construyen participaciones autorales entre las distintas firmas que se involucran, y que convergen todas en $E l$ artista (película y libro) como centro de imantación.

En el caso de las películas de Duprat y Cohn, la potencia de Laiseca y de su sistema de plagios interviene y marca la producción con sentidos y temas que se retomarán en películas posteriores, pues se exceden como meros directoresautores del proyecto. En el libro, Laiseca es intervenido a su vez por el autor del guión y ya desde las portadas se presenta la novela como mera adaptación, a pesar de que el plagio que realiza reenvía directamente a su proyecto y transforma la película y la filmografía posterior de la dupla Cohn-Duprat. Las intervenciones de la firma de Ferrari, además, desplazan la lógica del plagio en que podría leerse el libro hacia el de un "hacer" mutante y superpuesto que es correlativo de lo que Ferrari hace en la película, en el libro, en la productora y en la filmografía posterior de Duprat-Cohn, así como en su obra visual. Todas estas participaciones de las firmas habilitan que se lean diversas intencionalidades que pueden ser entendidas como autorales, por cuanto todas, desde perspectivas muy diferentes, significan hasta la multiplicidad una misma práctica con atribuciones subjetivantes y, hasta de valor cultural, complejas y paradojales. A tal punto que esta participación vuelve a instalar la misma pregunta sobre quién es el artista que la película pone en primer plano y nos deja en la respuesta de una multiplicidad que excede cualquier tipo de atribución unívoca de ese rol.

Para cerrar este trabajo, me interesa señalar, brevemente, que el mercado cultural es desestabilizado por este sistema autoral participativo que se sostiene en diversas performances autorales y actorales a partir de cada protagonista involucrado. En su libro El artista en el siglo XXI, Robert Morgan asegura que en el arte contemporáneo "los artistas que se mueven dentro de esta matriz funcionan en abstracto como un sistema de logotipos", en el cual "su valor fluctúa a menudo desprovisto de su contexto de significación"; de ahí que, como entra a jugar el dinero, "el argumento se aparta de la obra y se concentra casi exclusivamente en la mística del artista" (13). Laurent Jullier y Jean-Marc Leveratto, en Cinéfilos y 
cinefilias, sostienen que desde la constitución de una cinefilia cuyo nacimiento sitúan en los años treinta del siglo XX en Francia, hay dos sistemas de firmas que dotan de valor al filme: el cine de autor, relacionado con su dirección, y también el de las stars, que promovió "la transformación de nombres de artistas en lugares comunes de la calidad cinematográfica" (91). Sabemos por Arnold Hauser, entre otros, que en el caso de la producción escrita y visual el nombre de autor/ artista ligado a un individuo generó una revolución central en relación con su propia profesionalización desde el protomercado del Renacimiento; y según David Finkelstein y Alister McCleery, en la actualidad la autoría y su firma está cada vez más ligada a un espacio público complejo, mercantilizado y digital, que forma parte de una "integración vertical" de los productos mediáticos de los conglomerados multimedia (155). De modo que en las artes visuales contemporáneas se observa una lógica hegemónica publicitaria de los artistas basadas en el nombre propio; en el cine esto se dio desde principios de siglo XX por medio de un sistema de firmas de stars y directores-autores y la producción escrita tampoco escapó desde su inicio a la asociación entre firma y mercado. Por ende, la pregunta por quién es el artista articula estas condiciones de las artes en un momento donde ese mercado que permitió su profesionalización a partir de la firma, hoy hace de la misma y de sus conceptos, intencionalidades y singularidades, un sello y una marca identificables y consumibles.

Si bien el relato de El artista no deja de visibilizar cómo la firma y la consolidación de un estilo unívoco se convierten en una mercancía identificable que el mercado necesita controlar, clasificar e institucionalizar mediante dispositivos diversos, aprovechando los sistemas de valoración de las artes, al mismo tiempo su compleja atribución autoral somete - no solo la filmografía de los directores, sino las relaciones entre formatos de una misma obra- a una zona de mutación y variabilidad autoral, disciplinar y hasta "estética" que genera problemas de clasificación y de valoración unívocos para el mercado; pero también para la crítica que la película no deja de señalar en su relato como un agente fundamental e intermediario en esa relación. Con esto no quiero decir que El artista se sostenga en un sistema de producción fuera del mercado o que genere un sistema de producción al margen, como podría pensarse en la genial Historias extraordinarias de Mariano Llinás que, por otro lado, se estrenó el mismo año. De hecho, la coproducción internacional que interviene en su realización, con capitales italianos, uruguayos, argentinos, y que da cuenta de la transnacionalización de la producción cinematográfica contemporánea, la participación en festivales internacionales con premios obtenidos en los mismos, el apoyo del Instituto Nacional de Cine y Artes Audiovisuales, la participación de la propia 
productora de los directores, Televisión abierta, y la publicación del libro por la editorial transnacional Random House Mondadori dan cuenta de cómo se articulan actores del mercado muy fuertes en su realización. Lo que quiero decir es que, incluso desde el interior de esos mercados, ya hay signos evidentes de una inminencia que anticipa el final de su hegemonía sobre la producción artística, una inminencia que, sin embargo, también nos recuerda que no siempre el arte y el artista necesitaron del mercado y de sus firmas para "hacer". El artista es parte de un todavía imperceptible y minúsculo agrietamiento a la cooptación por la firma artística con la cual el mercado somete cada vez más el arte a sus sistemas de clasificación y venta.

\section{Obras citadas}

Aguilar, Gonzalo. Otros mundos. Buenos Aires: Santiago Arcos, 2012. Impreso.

Andermann, Jens. Nuevo cine argentino. Buenos Aires: Paidós, 2015. Impreso.

Balázs, Béla. El hombre invisible o la cultura del cine. Buenos

Aires: Cuenco de Plata, 2013. Impreso.

Batle, Diego. "El arte moderno está loco, loco, loco".

Otros cines. Web. 8 de agosto de 2015.

Bergara, Hernán, "El factor Laiseca". Por favor, iplágienme!

Buenos Aires: Eudeba, 2013. Impreso.

Barthes, Roland. "La muerte del autor". El susurro del lenguaje: más allá de la palabra y de la escritura. Buenos Aires: Paidós, 2002. 65-72. Impreso.

Bourriaud, Nicolás. Postproducción. Buenos Aires: Adriana Hidalgo, 2004. Impreso.

Bourriaud, Nicolás. Radicante. Buenos Aires: Adriana Hidalgo, 2009. Impreso.

Deleuze, Gilles. La imagen movimiento: estudios sobre cine

1. Buenos Aires: Paidós, 1984. Impreso.

Deleuze, Gilles. La imagen tiempo: estudios sobre cine 2.

Buenos Aires: Paidós, 1987. Impreso.

Derrida,Jacques. "Firma, acontecimiento, contexto". Márgenes de

la filosofía. Madrid: Cátedra, 1998. 347-372. Impreso.

Didi-Huberman, Georges. Lo que vemos, lo que nos mira.

Buenos Aires: Manantial, 2004. Impreso.

Duprat, Gastón y Andrés Cohn. "Esta película no busca dar respuestas". Página/12. 28 de mayo de 2009. Impreso.

Duprat, Gastón y Mariano Cohn. El artista (2008). Impreso.

Duprat, Gastón y Mariano Cohn. El hombre de al lado (2010). Impreso.

Duprat, Gastón y Mariano Cohn. Enciclopedia (2000). Impreso.

Duprat, Gastón y Mariano Cohn. Living Stars (2014). Impreso. 
Duprat, Gastón y Mariano Cohn. Querida, voy a comprar cigarrillos y vuelvo (2011). Impreso.

Fernández González, Carlos. "Alcances y dimensiones del plagio en la narrativa de Alberto Laiseca: alrededor de Por favor ;plágienme!"”. Revista Chilena de Literatura 87 (2014): 89-113. Impreso.

Finkel, Raúl. "Cohn y Duprat: El artista". Cinesinorillas. Web. 8 de agosto de 2015.

Finkelstein, David y Alistar McCleery. Una introducción a la historia del libro. Buenos Aires: Paidós, 2014. Impreso.

Foster, Hal. El retorno de lo real. Madrid: Akal, 2001. Impreso.

Foucault, Michel. ¿Qué es un autor? Buenos Aires: El Cuenco de Plata, 2010. Impreso.

García Canclini, Néstor y Carlos Moneta. Las industrias culturales en la integración latinoamericana. México: Grijalbo, 1999. Impreso.

Gardies, René, comp. Comprender el cine y las imágenes. Buenos Aires: La Marca Editora, 2014. Impreso.

Getino, Octavio. El capital de la cultura: las industrias culturales en la Argentina. Buenos Aires: Ciccus, 2008. Impreso.

Getino, Octavio. Cine iberoamericano: Los desafíos del nuevo milenio. Buenos Aires: Ciccus, 2007. Impreso.

Jullier, Laurent y Jean-Marc Leveratto. Cinéfilos y cinefilias. Buenos Aires: La Marca Editora, 2012. Impreso.

Krapp, Fernando. "Quedan los artistas". Página/12. 11 de julio de 2010. Impreso.

Laddaga, Reinaldo. "Algunas determinaciones del arte y las letras en años recientes". Literatura e realidade(s). Orgs. Heidrun Krieger Olinto y Karl Erik Schollhammer. Río de Janeiro: 7 Letras, 2009. 168-184. Impreso.

Laiseca, Alberto. Por favor, ;plágienme! Rosario: Beatriz Viterbo, 1991. Impreso.

Laiseca, Alberto et al. El artista. Buenos Aires: Mondadori, 2010. Impreso.

McNamara, Rafael, "El artista, de Gastón Duprat y Mariano Cohn". Cinevivo. Web. 8 de agosto de 2015.

Morgan, Robert. El artista en el siglo XXI: la era de la globalización. Buenos Aires: Eduntref, 2012. Impreso.

Moulin, Raymonde. El mercado del arte: mundialización y nuevas tecnologías. Buenos Aires: La Marca Editora, 2012. Impreso.

Piglia, Ricardo. Prólogo. Laiseca, Alberto. Los Sorias. Buenos Aires: Simurg, 1998. 9-13.

Prividera, Nicolás. El país del cine: para una historia política del nuevo cine argentino. Buenos Aires: Los Ríos, 2014. Impreso. 
Schwarzbök, Silvia. "La imposibilidad contemporánea de no retornar de lo real: la presencia de lo misterioso en el cine argentino reciente". La escena y la pantalla. Comps. Álvaro Fernández Bravo y Jens Andermann. Buenos Aires, Colihue, 2013. Impreso.

Soria, Carolina. "Perversión y perturbación de la mirada en El artista". Actas del II Congreso Internacional de la Asociación Argentina de Estudios de Cine y audiovisual. Buenos Aires, 2010. Impreso.

Speranza, Graciela. "Cohn \& Duprat en el aire". Otra Parte 9 (2006). Impreso. Topuzian, Marcelo. Muerte y resurrección del autor (19632005). Santa Fe: UNL, 2014. Impreso. 